NOTES AND CORRESPONDENCE

\title{
On the Kosa (Asian Dust) Event in November 2002: Aerosol Number Concentrations and Precipitation Chemistry in Toyama, Japan
}

\author{
Koichi WATANABE \\ Toyama Prefectural University, Kosugi-machi, Toyama, Japan \\ and
}

Hideharu HONOKI

Toyama Science Museum, Toyama, Japan

(Manuscript received 19 May 2003, in revised form 28 August 2003)

\begin{abstract}
The Kosa event was observed widely in Japan on 12 November 2002. Measurements of size-separated aerosol number concentrations and precipitation chemistry were performed in Toyama during the autumn and early winter of 2002 . The number of aerosol particles larger than $3.0 \mu \mathrm{m}$ in diameter dramatically increased during the Kosa event, whereas the number concentrations of finer particles hardly changed. The concentration of non-sea-salt calcium and $\mathrm{pH}$ were high in the precipitation sampled during the Kosa event.
\end{abstract}

\section{Introduction}

Kosa (Asian dust) particles are transported from the Asian continent over Japan, mainly during the spring seasons (Iwasaka et al. 1983), and not only affect radiation intensity in the atmosphere, but also contribute to the neutralization of acids in water droplets (Tsuruta 1991; Watanabe et al. 1999). On 12 November 2002, Kosa was widely seen in Japan (http:// www.jma.go.jp/JMA_HP/jma/index.html). Kosa events have been rarely observed in the autumn seasons. The total number of days when Kosa events were observed at the 123 weather stations in Japan during October and Novem-

Corresponding author: Koichi Watanabe, Toyama Prefectural University, Kosugi-machi, Toyama 939-0398, Japan.

E-mail: nabe@pu-toyama.ac.jp

(C) 2003, Meteorological Society of Japan ber is shown in Fig. 1. In autumn, Kosa had sometimes been seen in the early 1970 s, but hardly observed after 1975 . Kosa also was detected at some weather stations (6 points) in November 1996. In the case of November 2002, a total of 76 Japanese routine meteorological observatories reported Kosa events.

Observational studies on aerosol optical characteristics or number concentrations of aerosol particles during Kosa events have been performed in the spring seasons (Tanaka et al. 1989; Chun et al. 2001). Precipitation chemistry affected by Kosa particles has been examined (Dokiya et al. 1995; Minoura et al. 1998). Kosa or mineral particles also were studied by electron microscopy (Okada et al. 1987; Niimura et al. 1998). However, investigations on both aerosol number concentrations and precipitation chemistry during particular Kosa events rarely have been made. Moreover, there 


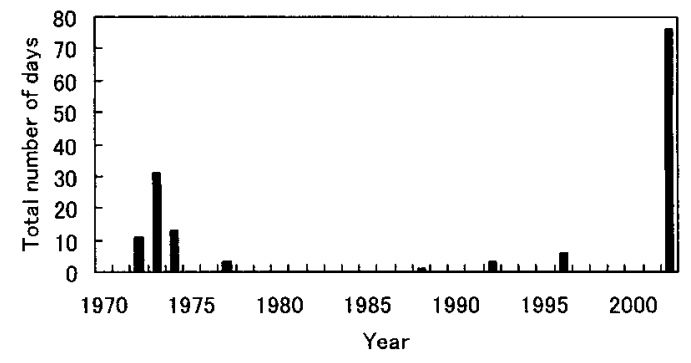

Fig. 1. Total number of days when Kosa events were observed at the weather stations in Japan (123 points) during October and November.

are no case studies on Kosa events during the autumn seasons in literature.

In this paper, characteristics of sizeseparated aerosol number concentrations and the chemical composition of precipitation in Toyama, Hokuriku district, located near the coastal region of the Japan Sea, during the Kosa event in the autumn 2002, are examined, and the effect of Kosa particles on the atmospheric environment, especially acidic precipitation is discussed.

\section{Methods}

Surface weather charts at $09 \mathrm{H}$ JST from 10 to 13 November 2002 are displayed in Fig. 2. A low pressure system over the continent on 10 November might have caused the dust storm, and developed after 11 November. Then, the low pressure passed through Japan, and the Kosa event was observed on 12 November.

The number concentrations of aerosol particles in the five diameter ranges of $d>0.3$, $0.5,1.0,3.0$ and $5.0 \mu \mathrm{m}$ were measured using a laser particle counter (Kanomax, Model 3886) with a $10 \mathrm{~mm}$ ID Tygon tube (100 cm length). The counter was set on the roof of the building of the college of Technology, Toyama Prefectural University at Kosugi-machi in Toyama. One-minute-averaged data were obtained every hour.

Bulk sampling of precipitation was performed at the Toyama Astronomical Observatory every 3-10 days. Figure 3 presents the map of Japan showing the locations of Toyama Prefectural University and Toyama Astronomical Observatory. After the sampling, the $\mathrm{pH}$ of the precipitation samples was measured by an electrode

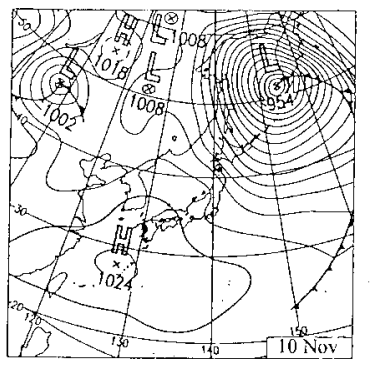

10

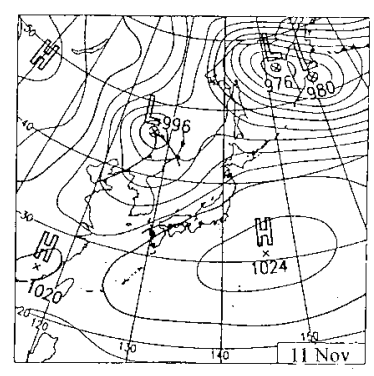

11
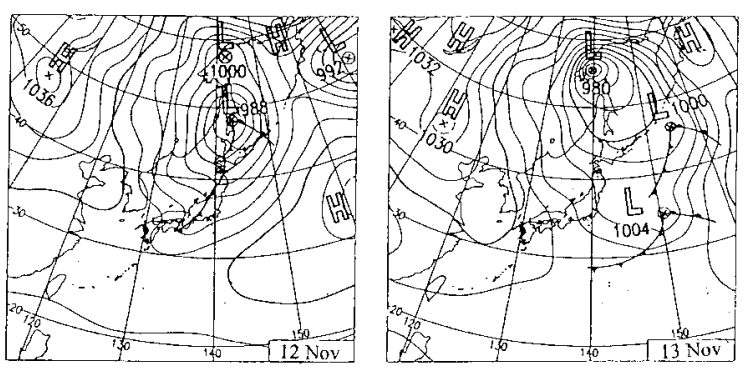

13

Fig. 2. Surface weather charts at $09 \mathrm{H}$ JST from 10 to 13 in November 2002.

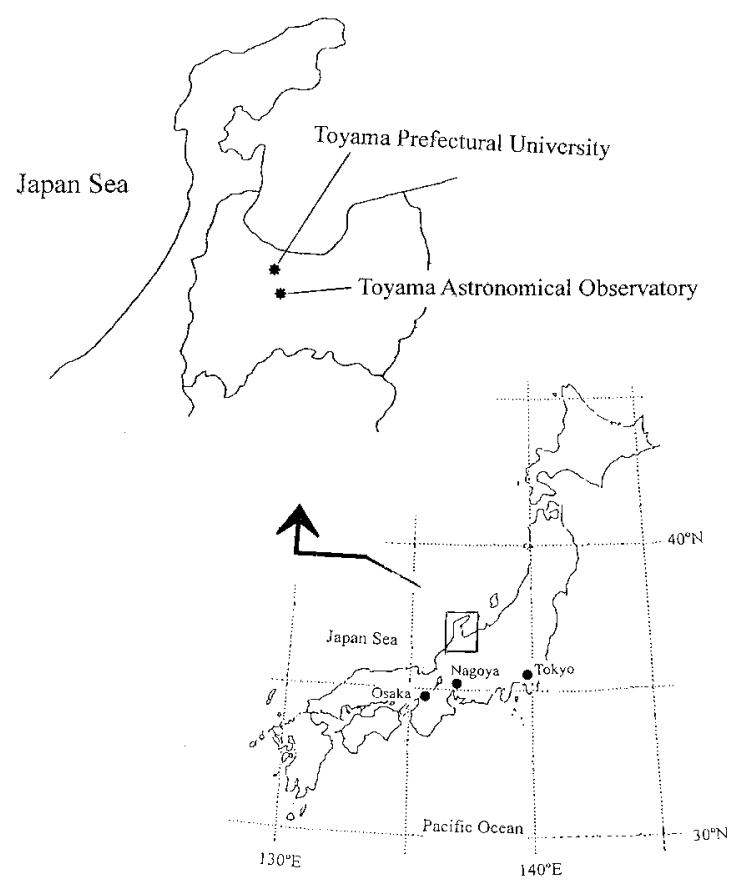

Fig. 3. Map of Japan showing the locations of Toyama Prefectural University and Toyama Astronomical Observatory. 
using a $\mathrm{pH}$ meter (Horiba, Model D-14). The accuracy was $\pm 0.01 \mathrm{pH}$. The analysis of dissolved ionic species was performed using an ion chromatograph (Shimadzu, non-suppressor type), equipped with an IC-A3 column to quantify $\mathrm{Cl}^{-}, \mathrm{NO}_{3}^{-}, \mathrm{SO}_{4}^{2-}$ and an IC-C3 column to quantify $\mathrm{Na}^{+}, \mathrm{NH}_{4}^{+}, \mathrm{K}^{+}, \mathrm{Mg}^{2+}$ and $\mathrm{Ca}^{2+}$. The eluent used was $8.0 \mathrm{mM} p$-hydroxybenzoic acid/ $3.2 \mathrm{mM}$ tris (hydroxymethyl) aminomethane/ $50 \mathrm{mM}$ boric acid for the anions, and $2.5 \mathrm{mM}$ oxalic acid for the cations. The analytical meth- ods were described in detail by Honoki et al. (2001). The mean analytical error was within $5 \%$.

\section{Results and discussion}

\subsection{Aerosol number concentrations}

Time series of the size-separated aerosol number concentrations at Kosugi-machi during November and December 2002 are shown in Fig. 4. Unfortunately, the number concentrations were not measured from the morning of
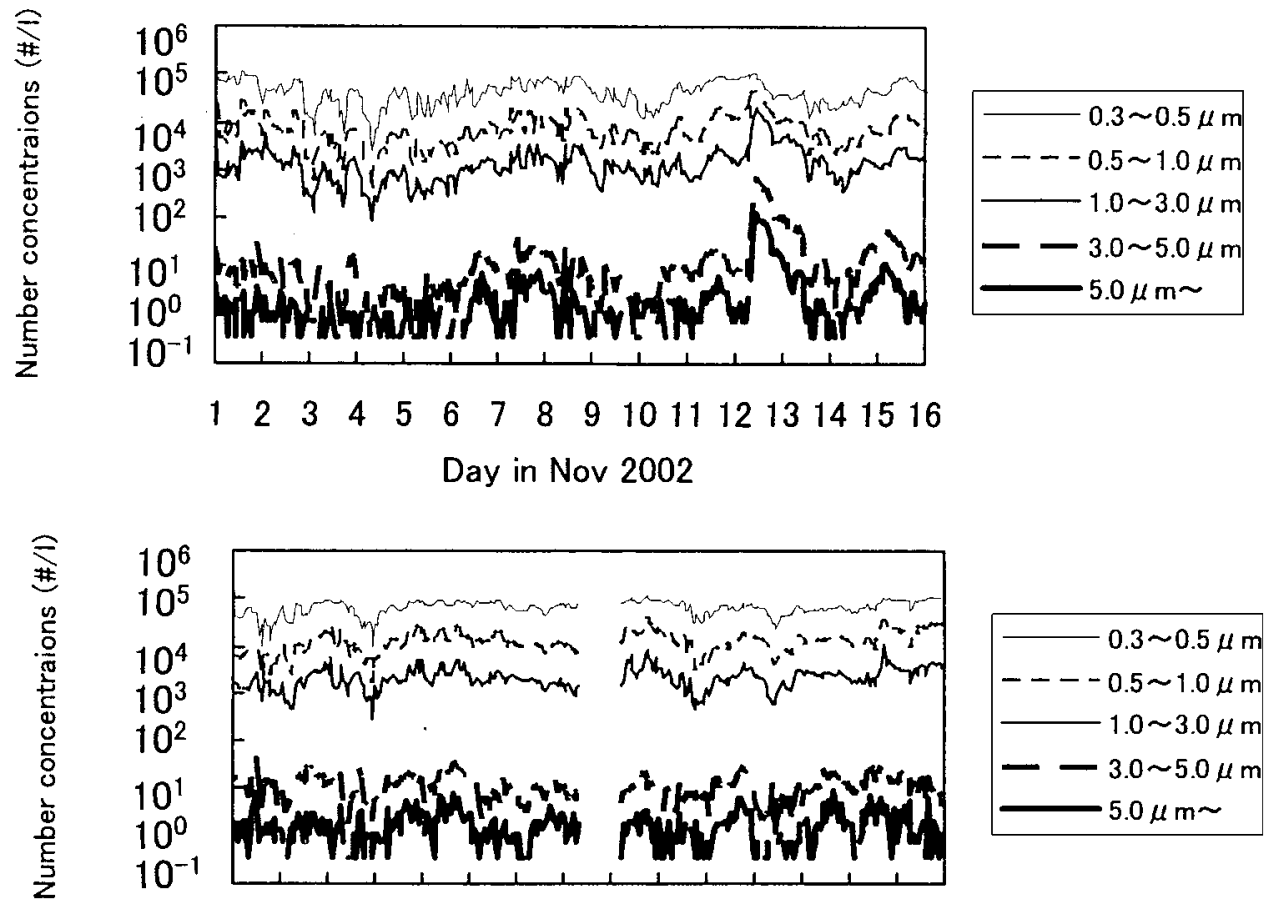

16171819202122232425262728293031

Day in Nov 2002

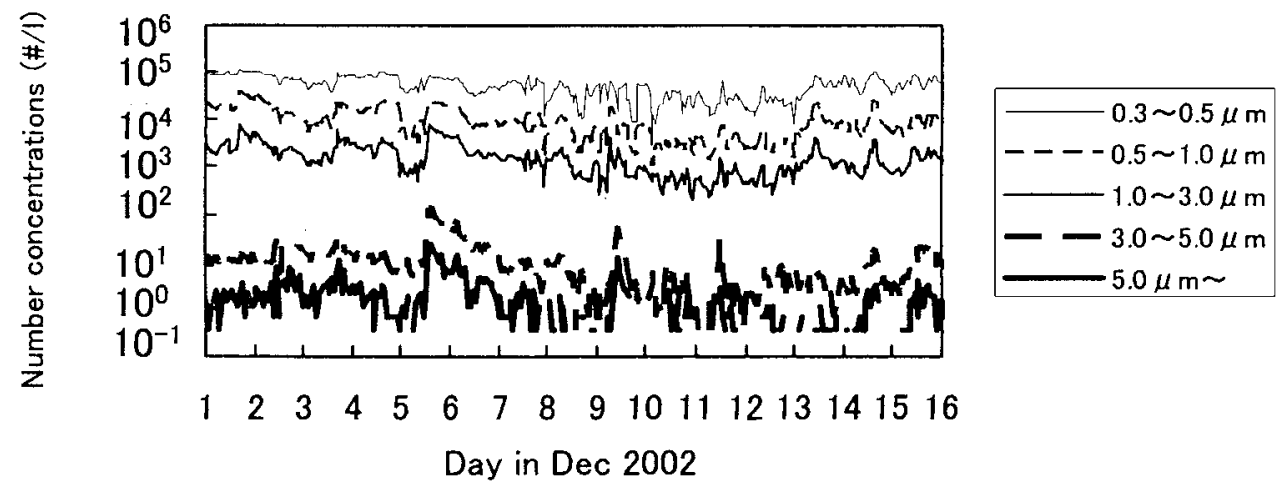

Fig. 4. Time series of the size-separated aerosol number concentrations at Kosugi-machi in Toyama during November and December 2002. 


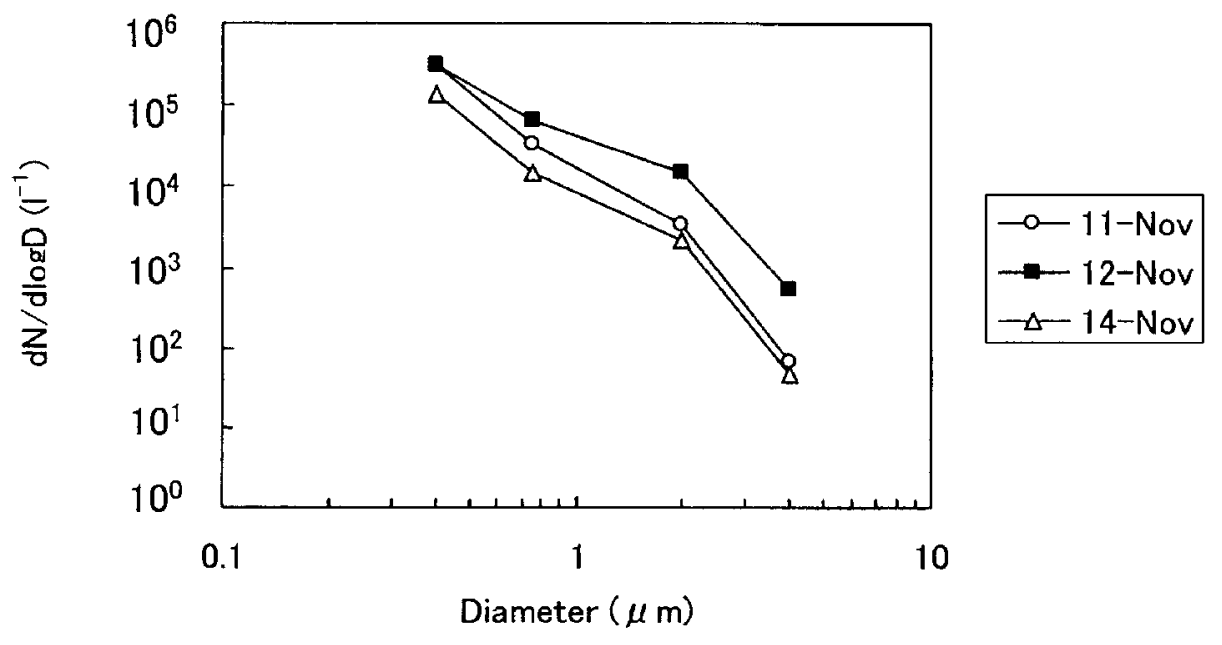

Fig. 5. Aerosol number concentrations for three different cases: on 11 November (before the Kosa event), 12 November (during the Kosa event) and 14 November (after the Kosa event).

23 to the morning of 24 in November due to electric trouble. The number of aerosol particles in the range of 3.0-5.0 was usually around $10 \ell^{-1}$. During the Kosa event, the number was near $1000 \ell^{-1}$. In the daytime of 12 November, the number concentrations of aerosol particles larger than $3.0 \mu \mathrm{m}$ abruptly increased whereas the aerosol number concentration in the range of $0.3-0.5 \mu \mathrm{m}$ hardly changed. The high concentrations of the larger particles continued until the morning of 13 November. After the daytime of 13 November, the number of concentrations decreased due to rain fall. The larger particles concentrations also rose abruptly on 5 December (Fig. 4). The relatively high concentrations continued until 6 December. Perhaps, the Kosa event might have occurred also.

The mean aerosol number concentrations for three different cases: on 11 November (before the Kosa event), 12 November (during the Kosa event) and 14 November (after the Kosa event), are presented in Fig. 5. The number concentrations of the fine particles $(0.3-0.5 \mu \mathrm{m})$ did not increased during the Kosa event. The coarse particles lager than $1.0 \mu \mathrm{m}$ dramatically increased. The particles in the range of 0.5$1.0 \mu \mathrm{m}$ also increased. After the Kosa event, the number concentrations were reduced. Chun et al. (2001) reported that during the dust period in Seoul, coarse particles $(1-10 \mu \mathrm{m})$ also in- creased, which implied that mineral dust is the major component, however, number concentrations for particles smaller than $1 \mu \mathrm{m}$ were reduced. The fine particles contain primary particles from combustion sources and secondary materials such as sulfate, nitrate and ammonium formed by gas-to-particle conversion (Seinfeld and Pandis 1998). Observation in Seoul is greatly affected by anthropogenic pollutants. Asian dust (Kosa) events are usually followed by the passage of strong frontal systems and the movement of air is fast (Chun et al. 2001). Therefore, the number of fine particles decreased during the dust episode in Seoul. Air quality in the city of Seoul seems to be more polluted than that at Kosugi-machi located in a rural (or semi-urban) area. The decrease in fine particles seems to be small considering the passage of the frontal system at Kosugi-machi, differing from the case in Seoul. Perhaps air pollution, including fine particles, might also have been transported with Kosa particles from the continent. As a result, the fine particle concentrations hardly changed. However, much more detailed research is required to understand the phenomenon.

\subsection{Precipitation chemistry}

A summary of the chemistry of the precipitation (mainly rain water) bulk sampled at Toyama Astronomical Observatory is shown 
Table 1. Summary of the chemistry of the bulk precipitation samples at Toyama Astronomical Observatory from October to December 2002. Units of the concentrations of ionic constituents are microequivalents per liter.

\begin{tabular}{|c|c|c|c|c|c|c|c|c|c|c|c|}
\hline Date & $\mathrm{pH}$ & $\mathrm{Cl}^{-}$ & $\mathrm{NO}_{3}^{-}$ & $\mathrm{SO}_{4}^{2-}$ & ${ }_{\mathrm{nss}} \mathrm{SO}_{4}^{2-}$ & $\mathrm{Na}^{+}$ & $\mathrm{NH}_{4}^{+}$ & $\mathrm{K}^{+}$ & $\mathrm{Mg}^{2+}$ & $\mathrm{Ca}^{2+}$ & $\mathrm{nss}^{2+}$ \\
\hline 6-12 Oct & 4.77 & 43.6 & 10.8 & 30.2 & 27.0 & 27.0 & 13.9 & 17.7 & 6.7 & 22.0 & 20.8 \\
\hline 12-23 Oct & 4.53 & 187.5 & 16.8 & 58.1 & 37.4 & 172.8 & 3.1 & 3.6 & 39.9 & 24.0 & 16.4 \\
\hline 23-26 Oct & 4.36 & 394.0 & 16.1 & 88.4 & 46.4 & 350.2 & 0.0 & 5.1 & 76.1 & 37.1 & 21.7 \\
\hline 26 Oct-3 Nov & 4.55 & 275.7 & 10.5 & 57.3 & 26.4 & 257.9 & 0.0 & 5.3 & 58.3 & 26.6 & 15.2 \\
\hline 3-10 Nov & 4.50 & 214.6 & 12.5 & 67.5 & 43.3 & 201.5 & 4.1 & 5.5 & 43.1 & 26.5 & 17.7 \\
\hline $10-17$ Nov & 5.13 & 400.5 & 20.2 & 99.5 & 55.6 & 366.7 & 1.2 & 9.8 & 87.4 & 81.8 & 65.6 \\
\hline $17-24$ Nov & 4.17 & 235.7 & 17.2 & 97.1 & 69.3 & 232.1 & 5.5 & 9.3 & 50.5 & 29.9 & 19.7 \\
\hline 24-27 Nov & 4.68 & 143.8 & 4.7 & 45.1 & 28.8 & 135.4 & 0.6 & 2.0 & 31.6 & 22.2 & 16.2 \\
\hline 27 Nov-1 Dec & 4.20 & 75.5 & 23.3 & 88.9 & 81.0 & 65.6 & 15.8 & 5.0 & 27.4 & 26.9 & 24.0 \\
\hline 1-8 Dec & 4.48 & 191.4 & 12.4 & 69.7 & 48.4 & 177.0 & 1.2 & 2.6 & 38.8 & 39.0 & 31.2 \\
\hline 8-15 Dec & 5.12 & 146.6 & 7.8 & 41.3 & 25.1 & 135.1 & 1.6 & 3.6 & 30.3 & 36.5 & 30.5 \\
\hline $15-22$ Dec & - & 107.3 & 13.2 & 81.3 & 70.4 & 91.6 & 13.0 & 3.8 & 24.4 & 20.5 & 16.5 \\
\hline
\end{tabular}

in Table 1. Units of the concentrations of ionic constituents are microequivalents per liter $(\mu$ eq/ $\ell$ ). Unfortunately, the $\mathrm{pH}$ of the precipitation sampled from 15-22 December could not be measured. The $\mathrm{pH}$ of the precipitation water ranged from 4.17 to 5.13. Most of the samples were acidified. The levels of non-sea-salt sulfate $\left({ }_{n s s} \mathrm{SO}_{4}^{2-}\right)$ and non-sea-salt calcium $\left({ }_{\mathrm{nss}} \mathrm{Ca}^{2+}\right)$ were estimated using the following equations:

$$
\begin{aligned}
& { }_{\mathrm{nss}} \mathrm{SO}_{4}^{2-}=\mathrm{SO}_{4}^{2-}-\left(\mathrm{SO}_{4}^{2-} / \mathrm{Na}^{+}\right)_{\text {seawater }} \cdot \mathrm{Na}^{+}, \\
& { }_{\mathrm{nss}} \mathrm{Ca}^{2+}=\mathrm{Ca}^{2+}-\left(\mathrm{Ca}^{2+} / \mathrm{Na}^{+}\right)_{\text {seawater }} \cdot \mathrm{Na}^{+},
\end{aligned}
$$

where $\left(\mathrm{SO}_{4}^{2-} / \mathrm{Na}^{+}\right)_{\text {seawater }}$ and $\left(\mathrm{Ca}^{2+} / \mathrm{Na}^{+}\right)_{\text {seawater }}$ are the concentration ratio of $\mathrm{SO}_{4}^{2-}$ to $\mathrm{Na}^{+}$and that of $\mathrm{Ca}^{2+}$ to $\mathrm{Na}^{+}$in seawater, which are 0.12 and 0.044 (equivalent ratio), respectively (Wilson 1975; Keene et al. 1986). The major components in the precipitation samples were $\mathrm{Cl}^{-}$ and $\mathrm{Na}^{+}$derived from sea-salt particles, with a similar equivalent ratio of seawater. The concentration ratio of $\mathrm{Mg}^{2+}$ to $\mathrm{Na}^{+}$also was similar to that of seawater. The ${ }_{n s s} \mathrm{SO}_{4}^{2-}$ and $\mathrm{NO}_{3}^{-}$ contributed to the acidification of the precipitation samples. The concentration of ${ }_{n s s} \mathrm{SO}_{4}^{2-}$ was much higher than that of $\mathrm{NO}_{3}^{-}$. Higher concentrations of ${ }_{n s s} \mathrm{SO}_{4}^{2-}$ in precipitation have been seen in the Hokuriku district especially during winter seasons (Honoki and Hayakawa 2001; Honoki et al. 2001). A similar result also was reported on cloud water chemistry over the Japan Sea (Watanabe et al. 2001a), whereas a higher $\mathrm{NO}_{3}^{-}$concentration in cloud water was seen near the industrial region in Japan (Watanabe et al. 2001b). According to Honoki and Hayakawa (2001), the contribution rate of ${ }_{n s s} \mathrm{SO}_{4}^{2-}$ originating from the Asian continent was about 0.5 in the coast of the Hokuriku district.

Kosa particles are rich in $\mathrm{CaCO}_{3}$ (Tsuruta 1991) and suppress acidification of rain and cloud water (Minoura et al. 1998; Watanabe et al. 1999 and 2001a). High concentrations of $\mathrm{Ca}^{2+}$ are detected in cloud and rain water that contain Kosa particles (Dokiya et al. 1995; Watanabe et al. 1999 and 2001a). The ${ }_{n s s} \mathrm{Ca}^{2+}$ in the precipitation samples might have contributed to the neutralization of acids. Variations of the concentration of ${ }_{\mathrm{nss}} \mathrm{Ca}^{2+}$ and acidity $(\mathrm{pH})$ in the precipitation are presented in Fig. 6. The concentration of ${ }_{n s s} \mathrm{Ca}^{2+}$ and $\mathrm{pH}$ were significantly high in the precipitation water sampled during 10-17 November when the Kosa event was observed. The acidic species in 


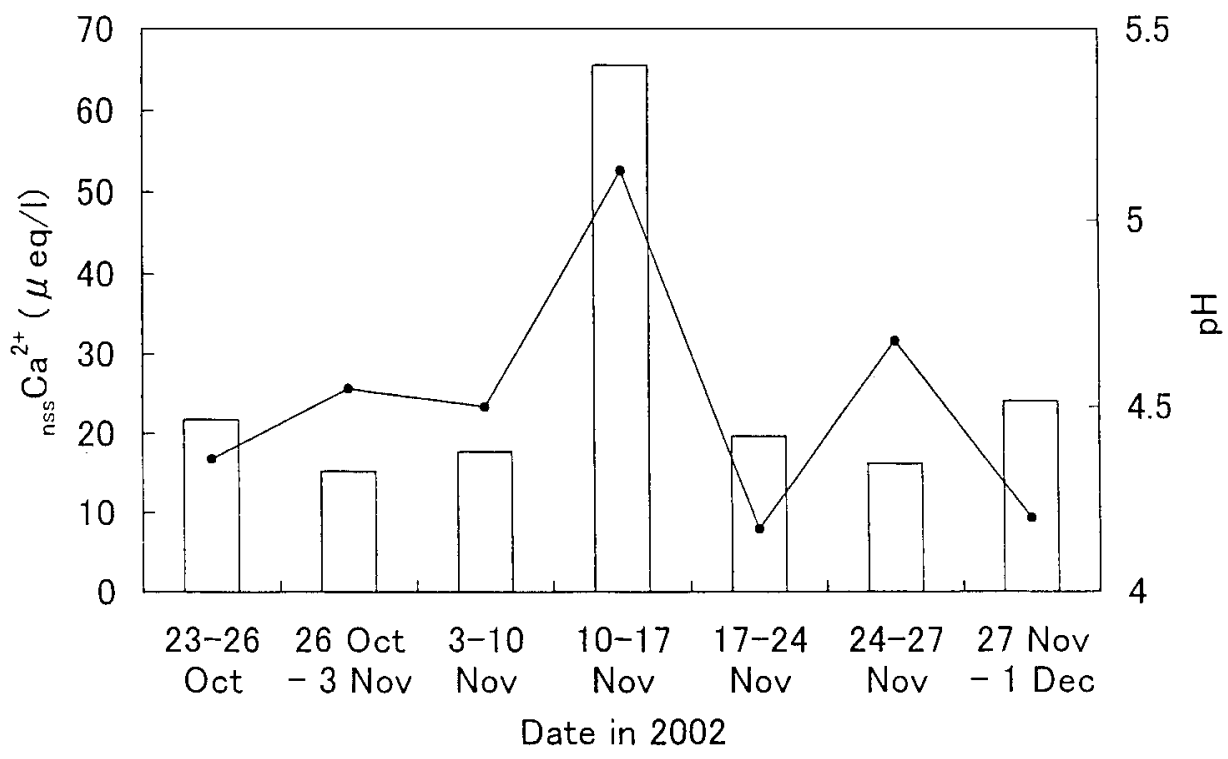

Fig. 6. Variations of the concentration of ${ }_{n s s} \mathrm{Ca}^{2+}$ (bar graph) and $\mathrm{pH}$ (line graph) in the precipitation sampled at the Toyama Astronomical Observatory in Toyama.

the precipitation were neutralized by the Kosa particles. As mentioned above, Kosa particles also might have been detected on 5 December. The ${ }_{n s s} \mathrm{Ca}^{2+}$ concentration was slightly high in the precipitation sampled on 1-8 December (Table 1). If Kosa events increase not only in the spring seasons but also in the autumn, then acidification of cloud and rain water would be suppressed, especially in the coastal regions of the Japan Sea.

\section{Summary}

Size-separated aerosol number concentrations and chemical composition of bulk sampled precipitation were measured in Toyama, Hokuriku district, located near the coastal region of the Japan Sea, during the autumn and early winter in 2002. The number concentrations of aerosol particles larger than $3.0 \mu \mathrm{m}$ in diameter significantly increased on 12 November when Kosa events were reported at the weather stations in Japan, and on 5 December. The high concentrations of large particles continued for the next few days. The fine particles smaller than $0.5 \mu \mathrm{m}$ hardly changed.

The precipitation water was usually acidified. However, the concentration of ${ }_{\mathrm{nss}} \mathrm{Ca}^{2+}$ and $\mathrm{pH}$ were high in the precipitation sampled during the Kosa event. If Kosa particles are transported frequently even in the autumn seasons, acidification of precipitation would be suppressed.

\section{Acknowledgments}

The authors thank Profs. K. Nakashima, I. Yasuda and T. Kawakami for their support of this study. Special thanks are extended to the members of the Toyama Astronomical Observatory.

\section{References}

Chun, Y., J. Kim, J.C. Choi, K.O. Boo, S.N. Oh and M. Lee, 2001: Characteristic number size distribution of aerosol during Asian dust period in Korea. Atmos. Environ., 35, 2715-2721.

Dokiya, Y., N. Miyakoshi, T. Hirooka, J. Yamashita, S. Ishikawa, M. Ohya and J. Sugaya, 1995: Long range transport of sulfur compounds over the Western North Pacific: deposition samples obtained on islands. J. Meteor. Soc. Japan, 75, 873-881.

Honoki, H. and K. Hayakawa, 2001: Origin of acidic components in precipitation in winter in the Hokuriku districts. J. Ecotechnol. Res., 7, 7983.

, K. Tsushima and K. Hayakawa, 2001: Inorganic constituents in snow accompanied by winter wind and their origin in the Hokuriku districts. J. Health Sci., 47, 559-564. 
Iwasaka, Y., H. Minoura and K. Nagaya, 1983: The transport and spatial scale of Asian dust-storm clouds: a case study of the dust-storm event of April 1979. Tellus, 35B, 189-196.

Keene, W.C., A.A.P. Pszenny, J.N. Galloway and M.E. Hawley, 1986: Sea-salt corrections and interpretation of constituent ratios in marine precipitation. J. Geophys. Res., 91, 6647-6658.

Minoura, H., S. Mizawa and Y. Iwasaka, 1998: Seasonal changes in the concentrations of major cations and anions in precipitations in urban Nagoya, Japan: local emission and long-range transport by Asian Dust Storms (KOSA) and Typhoons. J. Meteor. Soc. Japan, 76, 13-27.

Niimura, N., K. Okada, X.-B. Fan, K. Kai, K. Arao, G.-Y. Shi and S. Takahashi, 1998: Formation of Asian dust-storm particles mixed internally with sea salt in the atmosphere. J. Meteor. Soc. Japan, 76, 275-288.

Okada, K., A. Kobayashi, Y. Iwasaka, H. Naruse, T. Tanaka and O. Nemoto, 1987: Features of individual Asian dust-storm particles collected at Nagoya, Japan. J. Meteor. Soc. Japan, 65, $515-521$.

Seinfeld, J.H. and S.N. Pandis, 1998: Atmospheric Chemistry and Physics: From Air Pollution to Climate Change, Wiley Inter-science, New York, 1326pp.
Tanaka, M., T. Nakajima, M. Shiomara, M. Yamano and K. Arao, 1989: Aerosol optical characteristics in the yellow sand events observed in May 1982 at Nagasaki-Part I Observations. J. Meteor. Soc. Japan, 67, 267-278.

Tsuruta, H., 1991: Kosa, Water Research Institute Nagoya University, Kokonsyoin Tokyo, pp. 268-279. (in Japanese)

Watanabe, K., Y. Ishizaka and C. Takenaka, 1999: Chemical composition of fog water near the summit of Mt. Norikura in Japan. J. Meteor. Soc. Japan, 77, 997-1006.

, Y. Ishizaka and C. Takenaka, 2001a: Chemical characteristics of cloud water over the Japan Sea and the Northwestern Pacific Ocean near the central part of Japan: airborne measurements. Atmos. Environ., 35, 645-655.

, Y. Ishizaka, Y. Minami and K. Yoshida, 2001b: Peroxide concentrations in fog water at mountainous sites in Japan. Water, Air and Soil Pollut., 130, 1559-1564.

Wilson, T.R.S., 1975: Salinity and the major elements of sea water. In: Riley, J.P. and G. Skirrow (eds.), Chemical Oceanography, 2nd Edition, Vol. 1. Academic Press, Orland, pp. 365-413. 